\title{
Influence of SCOBY Microorganisms' Cultivation Conditions on the Synthesis Efficiency and Selected Qualities of Bacterial Cellulose
}

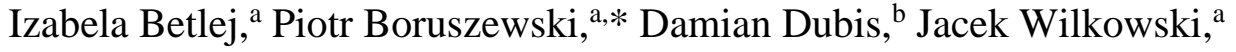
Krzysztof J. Krajewski, ${ }^{a}$ and Janusz Zawadzki ${ }^{\text {a }}$

This study examined how nutrients present in the growth environment of microorganisms forming a consortium of bacteria and yeasts, called a symbiotic culture of bacteria and yeast (SCOBY), affect the efficiency of cellulose synthesis and selected properties of the cellulose, such as gloss and color. The results showed that nitrogen-rich ingredients, such as peptone and green tea, increased the efficiency of polymer synthesis and determined the cellulose's gloss. This research showed that the qualitative characteristics of bacterial cellulose can be easily modified by the appropriate selection of the components of the culture media.
\end{abstract}

Keywords: Bacterial cellulose; CIELAB; Gloss units; SCOBY microorganisms

Contact information: a: Institute of Wood Sciences and Furniture, Warsaw University of Life Sciences (SGGW), 159 Nowoursynowska St., 02-776 Warsaw, Poland; b: Institute of Health and Economy,

Carpathian State College in Krosno, Krosno, Poland;

*Corresponding author: piotr_boruszewski@sggw.edu.pl

\section{INTRODUCTION}

Bacterial cellulose is a polymer produced by aerobic microorganisms, mainly bacteria belonging to Komagataeibacter (Yamada 2014). From a chemical point of view, it is the same polymer as plant cellulose, made of $\beta-1,4-\mathrm{D}$ glucopyranose units. However, unlike plant cellulose, bacterial cellulose is devoid of lignin and hemicellulose. Bacterial cellulose is also characterized by higher degrees of crystallinity and polymerization than plant cellulose. Depending on the cultivation conditions and the type of microorganisms used, the degree of crystallinity of the cellulose can range from 54\% to 92\% (Abdelraof et al. 2019; Zhang et al. 2020). Additionally, the handling conditions ofthe polymer, namely, its drying and conditioning, may effect changes in intra- and extra-molecular hydrogen bonds and consequently on the I $\alpha / \mathrm{I} \beta$ ratio of cellulose (Stanisławska 2016).

Bacterial cellulose fibers form a three-dimensional mesh structure. The size of a single fiber ranges from several to several dozen nm (Gündüz et al. 2015; Illa et al. 2019), classifying the bacterial cellulose structure as a nanomaterial. Undoubtedly, an important feature of bacterial cellulose, determining its use, is its high tensile strength and Young's modulus. Stanisławska et al. (2020) reported that the tensile strength of the bacterial polymer ranges from 200 to $300 \mathrm{MPa}$, while Indriyati et al. (2019) obtained a polymer with a tensile strength of almost $450 \mathrm{MPa}$. The Young's modulus of bacterial cellulose also depends on many factors, such as the culture conditions, method of purification, or drying of the polymer. Native, unmodified biocellulose has a Young's modulus ranging from 15 to $35 \mathrm{GPa}$ (Stanisławska et al. 2020). 
The composition of the culture medium and its $\mathrm{pH}$ also notably affect the efficiency of polymer synthesis (Çoban and Biyik 2011), the degree of polymerization (Tahara et al. 1997), and the water retention capacity (Muñoz-García et al. 2019). Betlej (2019) showed that bacterial cellulose obtained on a substrate rich in nitrogen-containing components is characterized by a greater number of layers and greater surface folding. With a more diverse substrate, the yield and weight of the synthesized cellulose also increases (Betlej and Krajewski 2019). The composition of the culture medium also influences the differences in intermolecular hydrogen bonds (Keshk and Sameshima 2006). Çaker et al. (2014) indicated that the use of ingredients of natural origin, such as molasses, as a substrate results in the synthesis of cellulose with a higher density than when using standard microbiological substrates.

The influence of growing conditions on cellulose properties is widely discussed in the literature (Amorim et al. 2019; Chen et al. 2019; Vigentini et al. 2019). The ingredients available in the growth medium of cellulose-synthesizing microorganisms and the growing conditions affect the physical characteristics of the polymer, such as gloss, color and thickness. Undoubtedly, the optimization of microbial cultivation conditions is one of the most important criteria determining the quality of the polymer and the directions of its application, but also determines the economic aspects of profitability of production. Highquality cellulose with appropriate physical or mechanical properties can be used in a wide variety of industries, for multiple applications (de Oliviera Barud et al. 2016; de Santana Costa et al. 2017).

The content and specific proportions of nutrients in the culture medium determine the efficiency of the cellulose synthesis process. Simple and readily available nutrients, such as tea extract or peptone, with the optimal amount of the carbon source, allow for good polymer synthesis efficiency; this is additionally characterized by a greater thickness of the film (Betlej et al. 2020) and better mechanical parameters (Yim et al. 2017). Undoubtedly, taking into account the intended use of bacterial cellulose, it is worth analyzing how the properties and characteristics of the polymer produced under certain conditions interact with each other. Uribe-Padilla et al. (2019) found that the thickness of the coating determines many of its characteristics, including gloss. Interesting observations on the influence of bacterial cellulose thickness on its optical properties were presented by Liu et al. (2018). The authors of the research indicated that under appropriate cultivation conditions it is possible to obtain ultra-thin biopolymer coatings with excellent optical properties.

This study assessed the influence of the culture conditions of a consortium of cellulose-synthesizing microorganisms, referred to as a symbiotic culture of bacteria and yeast (SCOBY), on selected quality characteristics of the obtained polymer, such as film thickness, gloss and color, and on the polymer synthesis efficiency. The goal was to find out whether the thickness of the polymer obtained under the given growth conditions determines the other tested property of the polymer, i.e. gloss. It seems, therefore, that the assessment of the interaction of the qualitative characteristics of bacterial cellulose, produced in specific cultivation conditions, will enable actions to be taken to optimize the cultivation process, in which a polymer with the characteristics specified for a given application is obtained. 


\section{EXPERIMENTAL}

\section{Materials}

The cellulose membranes subjected to the assessment of selected qualities were obtained from the cultivation of the microorganisms forming the SCOBY ecosystem (Ecological farm Wolanin, Szczawnik, Poland) on the substrates, the composition of which is presented in Table 1. The study used three types of nutrient substrates. Each of the culture media contained sucrose (Krajowa Spółka Cukrowa SA, Torun, Poland), and the media marked "B" and "C" contained nitrogen-rich ingredients: peptone (Biomaxima SA, Lublin, Poland) and green tea (Tata Global Beverages Polska Sp. z o.o., Warsaw, Poland). The culture media were sterilized in a steam autoclave.

Table 1. Substrate Compositions for the Cultivation of SCOBY Microorganisms

\begin{tabular}{|c|c|c|c|}
\hline Variant & $\begin{array}{c}\text { Sucrose (\%) } \\
(w / v)\end{array}$ & $\begin{array}{c}\text { Peptone (\%) } \\
(w / v)\end{array}$ & $\begin{array}{c}\text { Green Tea (\%) } \\
(w / v)\end{array}$ \\
\hline A1.5 & 1.5 & \multirow{5}{*}{ P } & \multirow{5}{*}{ ( } \\
\hline A2.5 & 2.5 & & \\
\hline A5.0 & 5.0 & & \\
\hline A7.0 & 7.0 & & \\
\hline A10.0 & 10.0 & & \\
\hline B1.5 & 1.5 & \multirow{5}{*}{0.025} & \multirow{5}{*}{0.01} \\
\hline B2.5 & 2.5 & & \\
\hline B5.0 & 5.0 & & \\
\hline B7.0 & 7.0 & & \\
\hline B10.0 & 10.0 & & \\
\hline C1.5 & 1.5 & \multirow{5}{*}{0} & \multirow{5}{*}{0.01} \\
\hline C2.5 & 2.5 & & \\
\hline C5.0 & 5.0 & & \\
\hline C7.0 & 7.0 & & \\
\hline C10.0 & 10.0 & & \\
\hline
\end{tabular}

\section{Methods}

The culture media were divided into $250-\mathrm{mL}$ aliquots, to which $1 \mathrm{~mL}$ of SCOBY inoculum was added. Cellulose-synthesizing microorganisms were cultured for $14 \mathrm{~d}$ in a heat incubator at a temperature of $26{ }^{\circ} \mathrm{C} \pm 2{ }^{\circ} \mathrm{C}$ and a relative air humidity of $68 \% \pm 2 \%$. After the end of the cultivation period, the produced cellulose was removed from the surface of the liquid. The cellulose was then cleansed of the remnants of the microorganism cells. The polymer purification procedure consisted of washing with detergent and then two rinses in distilled water. Subsequently, cellulose purification consisted of soaking in $0.1 \% \mathrm{NaOH}$, four rinses in water, subsequent rinsing in $0.1 \%$ citric acid, and another four rinses in water. After the purification process was completed, the polymer was dried at $28^{\circ} \mathrm{C} \pm 2{ }^{\circ} \mathrm{C}$ until the weight of the polymer did not change. The polymer drying process at a temperature less than $30{ }^{\circ} \mathrm{C}$ was planned based on the guidelines proposed by Domskiene et al. (2019). The dried membranes were stored in the dark. The dried polymer thickness was measured with an Extramess 2000 thickness gauge (Mahr, Göttingen, Germany). The obtained films were qualitatively assessed for properties such as gloss and color change. 
Assessment of gloss and color changes of bacterial cellulose

The gloss of the dried cellulose samples was assessed based on the requirements of EN 13722 (2004). A gloss meter was used for the tests (Zehntner ZGM 1120, Zehntner $\mathrm{GmbH}$ Testing Instruments, Sissach, Switzerland), and measurement geometries of $60^{\circ}$ and $20^{\circ}$ were used. Gloss tests were performed at 6 locations on each sample, and the test results were given in gloss levels. Color determination in the CIELAB system was performed using an SP60 spectrophotometer (X-Rite, Grand Rapids, MI, USA). The $L^{*}$, $a^{*}$ and $b^{*}$ parameters were determined and used to calculate the absolute color differences $(\Delta E)$ between the cellulose samples produced on the substrate with sucrose and the polymer samples produced on the substrates with nitrogen-rich substances (Eq. 1),

$$
\Delta E=\left(\left(L^{*_{0}}-L^{*_{1}}\right)^{2}+\left(a^{*_{0}}-a^{*_{1}}\right)^{2}+\left(b^{*_{0}}-b^{*_{1}}\right)^{2}\right)^{1 / 2}
$$

where $L^{*} 0, a^{*}{ }_{0}$ and $b^{*} 0$ are the color components of the cellulose derived from the SCOBY culture on the sucrose substrate, and $L^{*}{ }_{1}, a^{*}{ }_{1}$, and $b^{*}{ }_{1}$ are the color components of the cellulose derived from the SCOBY culture on the substrate with sucrose and ingredients rich in nitrogen. The color differences of the obtained polymers with different culture conditions were classified as follows: imperceptible difference $(0<\Delta E<1)$, difference noticed by an experienced observer $(1 \leq \Delta E<2)$, difference noticed by an inexperienced observer $(2 \leq \Delta E<3.5)$, clearly noticeable difference $(3.5 \leq \Delta E<5)$, and changed color impression $(5 \leq \Delta E)$.

\section{Evaluation of the cellulose synthesis efficiency of SCOBY microorganisms}

The assessment of cellulose synthesis efficiency was performed based on the methodological assumptions presented by Sharma and Bahardwaj (2019) and using Eqs. 2 and 3,

$$
\begin{aligned}
& S=m / M \\
& Y=(S / a) \times 100 \%
\end{aligned}
$$

where $S$ is the dry mass of polymer formed $(\mathrm{g} / \mathrm{L}), m$ is the mass of dried polymer $(\mathrm{g}), M$ is the volume of medium (L), $Y$ is the percentage of synthesis from 1 liter of growth medium $(\% / \mathrm{L})$, and $a$ is the sum of the initial concentration of sucrose and additional components $(g)$.

\section{Statistical analysis}

The obtained results were analyzed statistically using the STATISTICA (version 13) program (TIBCO Software Inc., Palo Alto, CA, USA). Main effects were investigated by analysis of variance (ANOVA).

\section{RESULTS AND DISCUSSION}

The results showed that both the variable content of sucrose in the growth media of the cellulose-synthesizing microorganisms and the addition of nitrogen-rich ingredients to the culture media significantly influenced the degree of gloss of the obtained cellulose film (Table 2). 
Table 2. Influence of Substrate Components on Selected Qualities of Bacterial Cellulose (ANOVA)

\begin{tabular}{|c|c|c|c|c|c|c|}
\hline Factor & $\begin{array}{c}\text { Degrees } \\
\text { of } \\
\text { Freedom }\end{array}$ & SS & MS & F & p & Pc (\%) \\
\hline $\begin{array}{c}\text { Sucrose } \\
\text { content }\end{array}$ & 2 & 7626.01 & 481.57 & 17.771 & 0.000003 & 10.0 \\
\hline $\begin{array}{c}\text { Addition of } \\
\text { peptone/tea }\end{array}$ & 2 & 963.15 & 3813.00 & 140.705 & 0.000000 & 78.8 \\
\hline
\end{tabular}

SS - sum of squares; MS - mean square; F - F-ratio; $p$ - p-value; Pc - percentage of

contribution. Statistical analyses were performed for the significance level $p=0.05$.

The statistical data showed that the addition of nitrogen-rich components significantly affected the gloss degree of the obtained cellulose films, which was expressed by a high $\mathrm{P}_{\mathrm{c}}$ factor $(78.8 \%)$. Thus, the quality of the culture medium determined the quality parameters of the polymer synthesized by the microorganisms.

Figures $1(\mathrm{a}, \mathrm{b}, \mathrm{c})$ show that there were clear differences between thegloss degree values of the polymer samples obtained from the culture media with different levels of sucrose and those from the media to which peptone and tea were added. The high coefficients of determination obtained in the tests showed that the varying sucrose content and the presence of nitrogen-rich components determined the gloss degrees of the polymers obtained on these substrates. An interesting observation was made regarding the gloss. The more sucrose in the nutrient medium, the lower was the gloss of the resulting polymer. Cellulose produced on the peptone substrate was characterized by the greatest decrease in the degree of polymer gloss, which suggests that the component rich in nitrogen may affect the tested property of the polymer.

In the scientific literature, there are examples of the gloss analysis of various types of polymers containing bacterial cellulose in their structure (Santos et al. 2016, 2017). An example of the assessment of the gloss of cellulose synthesized on a substrate with the addition of various polymers is that of Santos et al. (2017). The authors of the research indicated that the composition of the substrate clearly influences thegloss degree of the cellulose.

Due to the fact that bacterial cellulose of different thickness was obtained on different culture media used in the study, an attempt was made to explain the actual factor that determines the gloss of cellulose. Since in previous studies it was found that with a high sucrose content in the substrate and the addition of nutrient-rich ingredients, significantly thicker polymer layers are obtained (Betlej et al. 2020), attempts were made to assess whether the actual factor affecting the gloss of cellulose is its thickness or the composition of the substrate on which the polymer is synthesized. The evaluation of the correlation between the polymer thickness and its gloss made it possible to state that there was a very high relationship between the indicated features (Fig. 2 a, b, c). An interesting observation is the fact that as the film thickness increased, its gloss level decreased. Thus, on nutrient-rich substrates, on which relatively thick polymer layers are obtained, cellulose films with low gloss or even matt can be obtained. This observation should be considered important because it allows for very precise design of the conditions of bacterial cellulose synthesis, in which optimal polymer properties are obtained, useful for specific applications. 

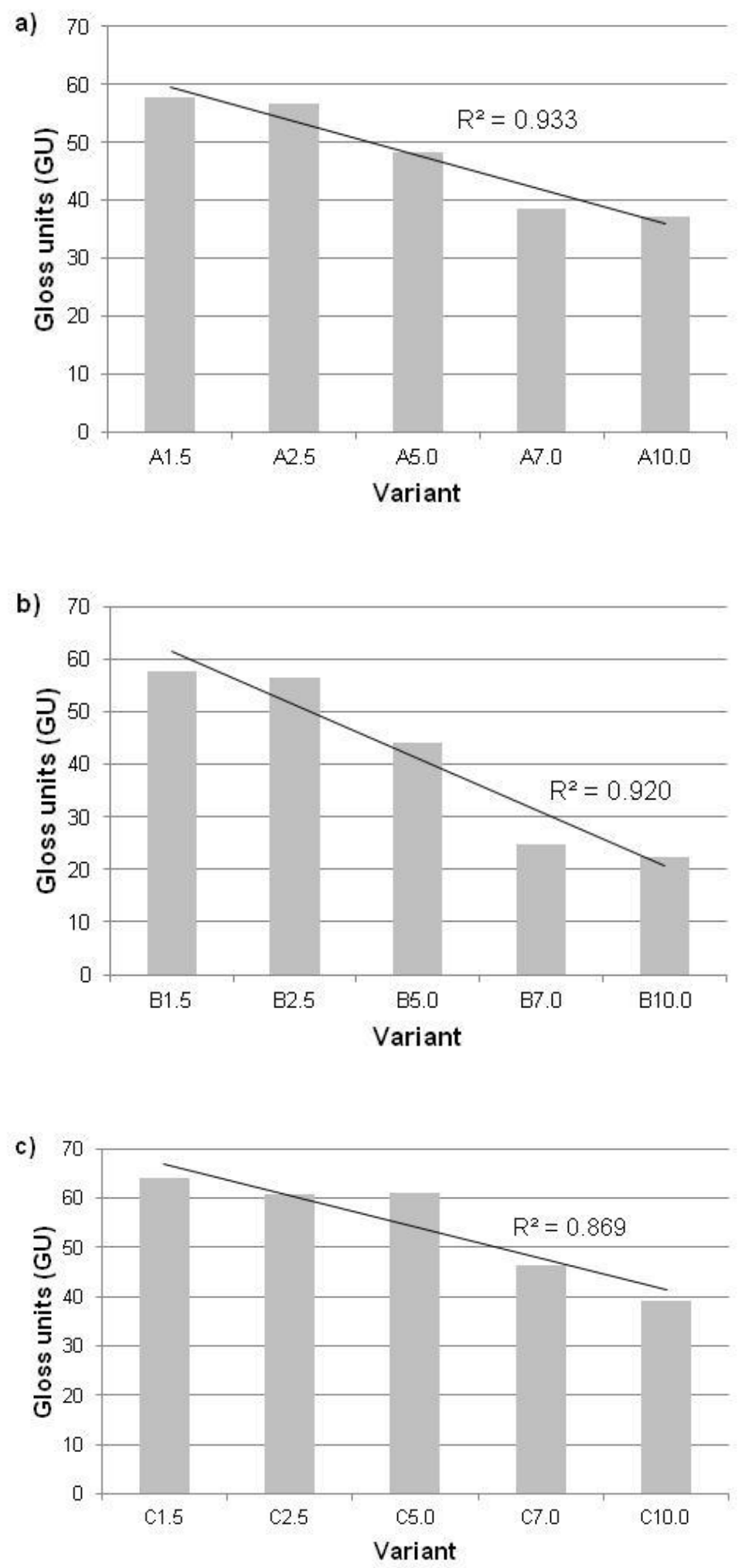

Fig. 1. Gloss degrees of bacterial cellulose obtained on substrates with: a) various sucrose contents, b) various contents of sucrose and constant of peptone, c) various contents of sucrose and constant green tea content 

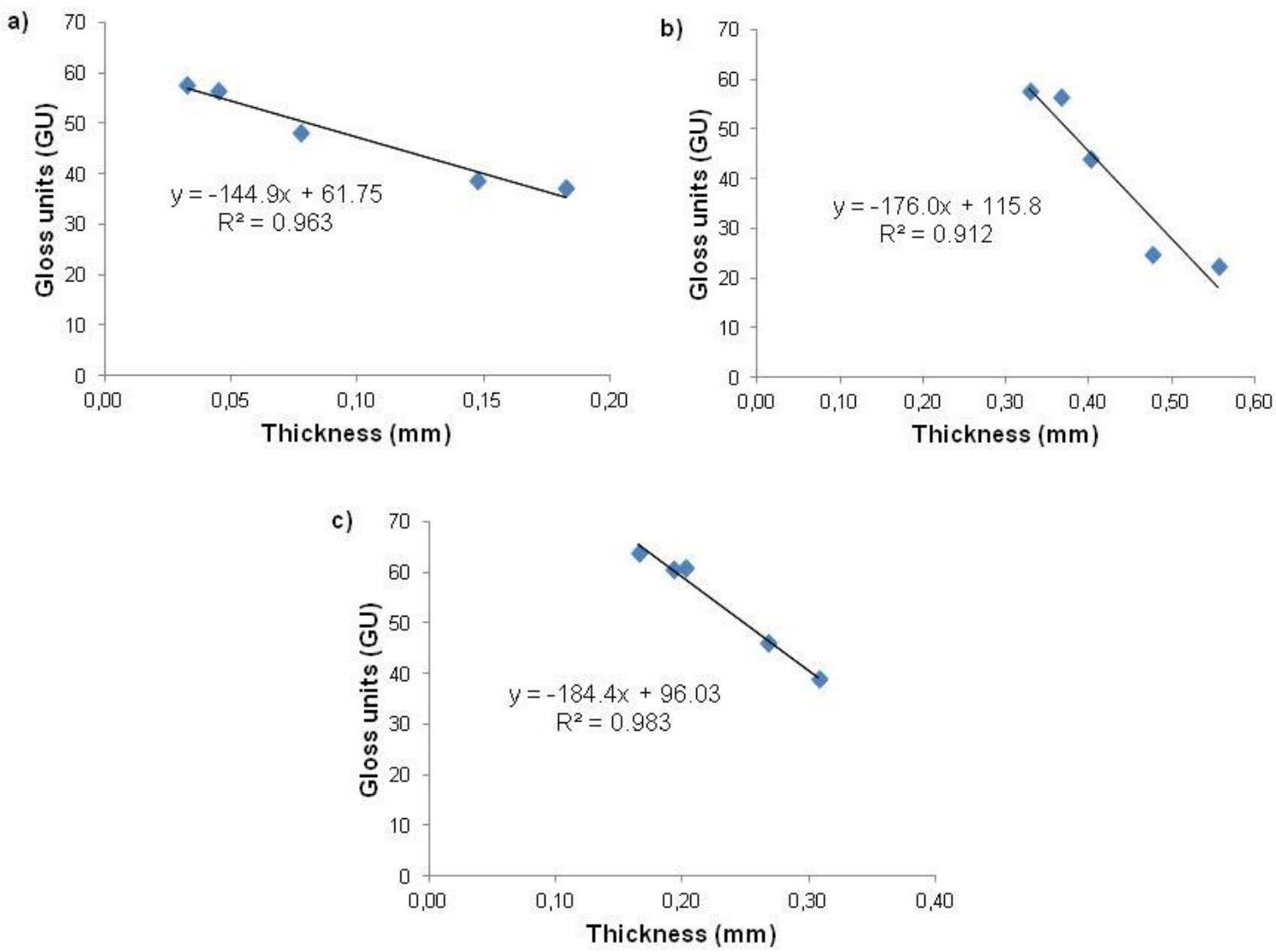

Fig. 2. Relationship between thickness and gloss of cellulose obtained on a substrate with: a) various sucrose contents, b) various contents of sucrose and constant of peptone, c) various contents of sucrose and constant green tea content

The addition of nitrogen-rich substances to the substrates caused color changes in the obtained cellulose membranes. The additions of both tea and peptone caused the color differences in most of the analyzed cases to be greater than 5, indicating that there was a color change in the polymer samples. Meanwhile, as the sucrose content in the substrate increased, the color differences between the samples obtained on the substrates without and with the addition of nitrogen-rich substances decreased (Fig. 3). The authors of the research suggest that there may be a relationship between the drying time and the color of the obtained polymer. During the experiment, it was noticed that a longer drying time of the cellulose, due to greater sample weight and higher water content of the polymer, caused the polymer to darken. However, the explanation of this phenomenon requires a separate experiment on the effect of drying conditions on the properties of bacterial cellulose. Kongruang (2008) also observed the influence of substrate composition on changes in the color of cellulose. The impact of drying temperature on changes on the transparency of bacterial cellulose was presented by Zeng et al. (2014).

Based on the obtained test results, the composition of the substrate determined the color of the polymer. Yim et al. (2017) observed differences in the colors of polymers obtained on substrates containing various types of nitrogen sources. The authors of the study also found that the type of carbon source in the culture medium influences the whiteness index of the synthesized cellulose. In addition, Jeong (2010) stated that the temperature at which cellulose synthesis occurs may affect its color. 

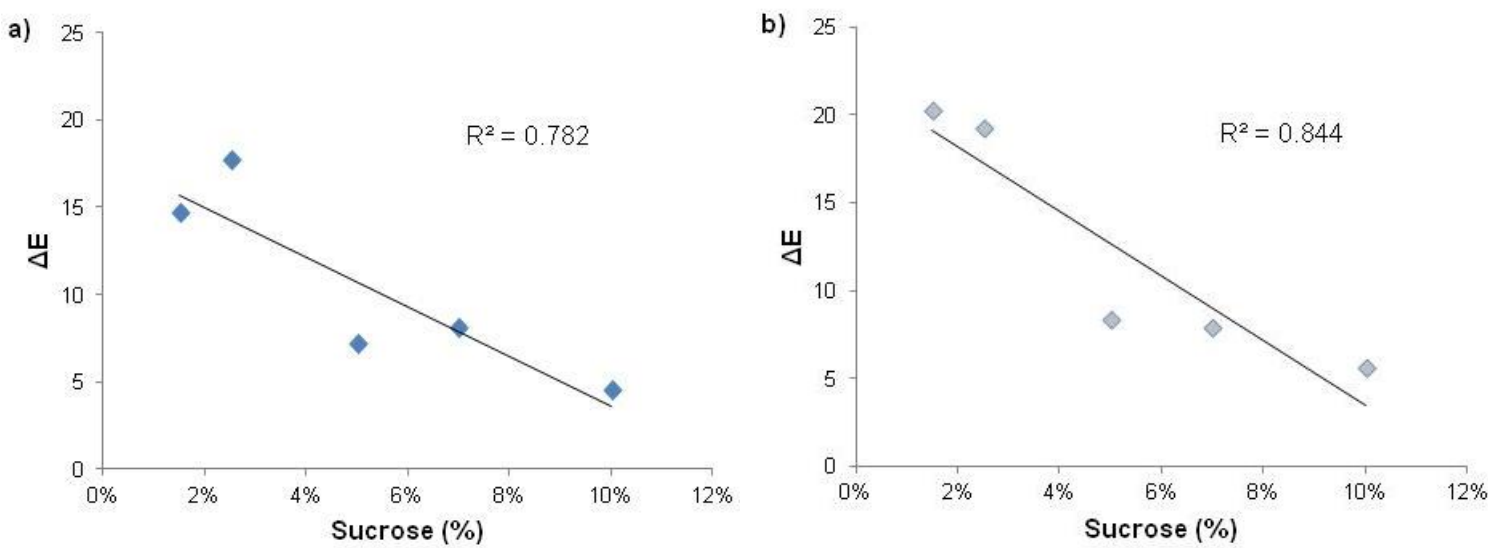

Fig. 3. Color differences $(\Delta E)$ of cellulose samples obtained on substrates with various sucrose contents and: a) with peptone, b) with green tea and peptone

The composition of the microbiological substrate significantly affected the efficiency of bacterial cellulose synthesis. Higher efficiency of cellulose synthesis was found with increasing sugar concentration in the microorganism growth media. The addition of peptone also significantly improved the efficiency of polymer synthesis (Table 4). The statistical data showed that the addition of nitrogen-rich components significantly influenced the efficiency of polymer synthesis (Table 5). In the scientific literature, one can find the results of studies on the influences of various carbon and nitrogen sources on the improvement of the efficiency of bacterial cellulose synthesis (Costa et al. 2017; Zhu et al. 2019). Research has shown that the addition of certain substances, such as peptone or yeast extract, may positively affect the efficiency of cellulose synthesis (Mangayil et al. 2021). Revin et al. (2018) compared the bacterial cellulose synthesis efficiencies of three types of substrates (synthetic substrates, substrates rich in organic and mineral components, and waste substrates from the food industry) and found that increased nutrients in the microorganism growth environment resulted in higher polymer synthesis efficiency. The effects of glucose addition on the quality parameters and the efficiency of bacterial cellulose synthesis were studied by Sharma and Bahardwaj (2019). The authors of the study indicated that there is a certain concentration of saccharide at which the efficiency of polymer synthesis is the highest. Interesting observations regarding the influences of different concentrations of fructose, glucose, and sucrose on the efficiency of cellulose synthesis were presented by Molina-Ramírez et al. (2017). The cited authors showed that the concentration and type of saccharide used affects the efficiency of polymer synthesis, but the type of carbon source used does not affect the quality characteristics of the polymer.

Table 4. Efficiency of Bacterial Cellulose Synthesis on Various Culture Media

\begin{tabular}{|c|c|c|c|c|c|c|}
\hline \multirow{2}{*}{$\begin{array}{c}\text { Sucrose } \\
\text { Content } \\
(\%)\end{array}$} & \multicolumn{2}{|c|}{ A1.5 to A10.0 } & \multicolumn{2}{|c|}{ B1.5 to B10.0 } & \multicolumn{2}{|c|}{$\mathrm{C} 1.5$ to $\mathrm{C} 10.0$} \\
\hline & $\mathbf{Y}$ & SD & $\mathbf{Y}$ & SD & $\mathbf{Y}$ & SD \\
\hline 1.5 & 27.864 & \pm 1.608 & 100.506 & \pm 10.478 & 90.508 & \pm 6.839 \\
\hline 2.5 & 26.038 & \pm 3.379 & 119.620 & \pm 5.938 & 111.336 & \pm 10.495 \\
\hline 5.0 & 33.608 & \pm 7.213 & 133.316 & \pm 8.051 & 110.656 & \pm 10.247 \\
\hline 7.0 & 40.172 & \pm 5.904 & 176.114 & \pm 14.997 & 132.388 & \pm 8.162 \\
\hline 10.0 & 53.572 & \pm 2.861 & 219.524 & \pm 13.932 & 159.546 & \pm 18.451 \\
\hline
\end{tabular}


Table 5. Influence of Substrate Components on the Efficiency of Bacterial Cellulose Synthesis (ANOVA)

\begin{tabular}{|c|c|c|c|c|c|c|}
\hline Factor & $\begin{array}{c}\text { Degrees } \\
\text { of } \\
\text { Freedom }\end{array}$ & SS & MS & F & p & Pc (\%) \\
\hline $\begin{array}{c}\text { Sucrose } \\
\text { content }\end{array}$ & 2 & 20082.9 & 10041.4 & 40.585 & 0.000000 & 11.8 \\
\hline $\begin{array}{c}\text { Addition of } \\
\text { peptone/tea }\end{array}$ & 2 & 140560 & 70280 & 284.055 & 0.000000 & 82.4 \\
\hline
\end{tabular}

SS - sum of squares; MS - mean square; F - F-ratio; $p$ - p-value; Pc-percentage of contribution. Statistical analyses were performed for the significance level $p=0.05$.

\section{CONCLUSIONS}

1. There was a clear correlation between the degree of gloss and the thickness of the bacterial cellulose film. The thickness of the polymer can be modified by appropriate selection of the nutrients in the substrate.

2. As the thickness of the cellulose increased, its gloss level decreased. Low gloss cellulose was obtained from nutrient-rich substrates.

3. By appropriate selection of nutrients necessary for the cultivation of SCOBY microorganisms, it is possible to design specific characteristics of the polymer, such as the thickness of the layer and the gloss depending on the thickness.

4. The addition of nitrogen-rich substances such as peptone and green tea significantly improved the cellulose synthesis efficiency.

5. The content of sucrose in the growth medium of the cellulose-synthesizing SCOBY microorganisms affects the color difference between the polymer samples.

6. A smaller difference in the color of bacterial cellulose was observed between the cellulose samples obtained on a substrate rich in sucrose and the cellulose samples obtained on also sugar-rich substrates and additionally containing peptone and tea extract.

\section{ACKNOWLEDGMENTS}

The authors thank Warsaw University of Life Sciences (SGGW) for financial support.

\section{REFERENCES CITED}

Abdelraof, M., Hasanin, M.S., and El-Saied, H. (2019). "Ecofriendly green conversion of potato peel wastes to high productivity bacterial cellulose," Carbohydrate Polymers 211, 75-83. DOI: 10.1016/j.carbpol.2019.01.095

Amorim, J. D. P., Costa, A. F. S., Galdino, Jr., C. J. S., Vinhas, G. M., Santos, E. M. S., 
and Sarubbo, L. A. (2019). "Bacterial cellulose production using fruit residues as substrate to industrial application," Chemical Engineering Transactions, 74, 11651170. DOI: $10.3303 / C E T 1974195$

Betlej, I., Salerno-Kochan, R., Krajewski, K.J., Zawadzki, J., and Boruszewski, P. (2020). "The influence of culture medium components on the physical and mechanical properties of cellulose synthesized by kombucha microorganisms," BioResources 15(2) 3125-3135. DOI: 10.15376/biores.15.2.3125-3135

Betlej, I. (2019). "Studies on the diversity of substrate composition in the culture medium of kombucha microorganisms and its influence on the quality of synthesized cellulose," Annals of Warsaw University of Life Sciences SGGW (Forestry and Wood Technology) 108, 21-25. DOI: 10.5604/01.3001.0013.7676

Betlej, I., and Krajewski, K. J. (2019). "Bacterial cellulose synthesis by kombucha microorganisms on a medium with a variable composition of nutrients," Annals of Warsaw University of Life Sciences SGGW (Forestry and Wood Technology) 108, 5357. DOI: 10.5604/01.3001.0013.7681

Çaker, F., Özer, I., Aytekin, A.Ö., and Şahin, F. (2014). "Improvement production of bacterial cellulose by semi-continuous process in molasses medium," Carbohydrate Polymers 106, 7-13. DOI: 10.1016/j.carbpol.2014.01.103

Chen, G., Wu, G., Chen, L., Wang, W., Hong, F. F., and Jönsson, L. J. (2019). "Comparison of productivity and quality of bacterial nanocellulose synthesized using culture media based on seven sugars from biomass," Microbial Biotechnology 12(4), 677-687. DOI: 10.1111/1751-7915.13401

Çoban, E. P., and Biyik, H. (2011). "Effect of various carbon and nitrogen sources on cellulose synthesis by Acetobacter lovaniensis HBB5," African Journal of Biotechnology 10(27), 5346-5354. DOI: 10.5897/AJB10.1693

Costa, A. F. S., Almeida, F. C. G., Vinhas, G. M., and Sarubbo, L. A. (2017). "Production of bacterial cellulose by Gluconacetobacter hansenii using corn steep liquor as nutrient sources," Frontiers in Microbiology 8, 2027. DOI: 10.3389/fmicb.2017.02027

de Oliviera Barud, H. G., da Silva, R. R., da Silva Barud, H., Tercjak, A., Gutierrez, J., Lustri, W. R., de Oliviera Jr., O. B., and Liberio, S. J. L. (2016). "A multipurpose natural and renewable polymer in medical applications: Bacterial cellulose," Carbohydrate Polymers 135, 406-420. DOI: 10.1016/j.carbpol.2016.07.059

de Santana Costa, A. F., Rocha, M. A. V., and Sarubo L. A. (2017). "Review - bacterial cellulose: An ecofriendly biotextile," International Journal of Textile and Fashion Technology 7(1), 11-26

Domskiene, J., Sederaviciute, F., and Simonaityte, J. (2019). "Kombucha bacterial cellulose for sustainable fashion," International Journal of Clothing Science and Technology 31(5), 644-652. DOI: 10.1108/IJCST-02-2019-0010

EN 13722 (2004). "Furniture - Assessment of the surface gloss," European Committee for Standardization, Brussels, Belgium

Gündüz, G., Aşık, N., Aydemir, D., and Kılıç, A. (2015). "Bakteriyel selülozüretimivekarakterizasyonu [The production and characterization of bacterial cellulose]," Ormancılık Dergisi 10(2), 1-10

Illa, M. P., Sharma, C. S., and Khandelwal, M. (2019). "Tuning the physiochemical properties of bacterial cellulose: Effect of drying conditions," Journal of Materials Science 54(18), 12024-12035. DOI: 10.1007/s10853-019-03737-9

Indriyati, I., Irmawati, Y., and Puspitasari, T. (2019). "Comparative study of bacterial 
cellulose film dried using microwave and air convection heating," Journal of Engineering and Technological Sciences 51(1), 121-132. DOI:

10.5614/j.eng.technol.sci.2019.51.1.8

Jeong, I. S. (2010). A Comparative Study on Chemical Components and Physiological Active Function of GreenTea and Black Tea, Master's Dissertation, Wonkwang University, Iksan, South Korea

Keshk, S., and Sameshima, K. (2006). "The utilization of sugar cane molasses with/without the presence of lignosulfonate for the production of bacterial cellulose," Applied Microbiology and Biotechnology 72(2), 291-296. DOI: 10.1007/s00253-0050265-6

Kongruang, S. (2008). "Bacterial cellulose production by Acetobacter xylinum strains from agricultural waste products," Applied Biochemistry and Biotechnology 148(1-3), 245-256. DOI: 10.1007/s12010-007-8119-6

Liu, F., McMaster, M., Mekala, S., Singer, K., and Gross, R.A. (2018). “Grown ultrathin bacterial cellulose mats for optical applications," Biomacromolecules 19(12), 45764584. DOI: 10.1021/acs.biomac.8b01269

Mangayil, R., Rissanen, A. J., Pammo, A., Guizelini, D., Losoi, P., Sarlin, E., Tuukkanen, S., and Santala, V. (2021). "Characterization of a novel bacterial cellulose producerfor the production of eco-friendly piezoelectric-responsive films from a minimal medium containing waste carbon," Cellulose 28, 671-689. DOI: $10.1007 / \mathrm{s} 10570-020-03551-6$

Molina-Ramírez, C., Castro, M., Osorio, M., Torres-Taborda, M., Gómez, B., Zuluaga, R., Gómez, C., Gañán, P., Rojas, O. J., and Castro, C. (2017). "Effect of different carbon sources on bacterial nanocellulose production and structure using the low pH resistant strain Komagataeibacter medellinensis," Materials 10(6). DOI: 10.3390/ma10060639

Muñoz-García, J. C., Corbin, K. R., Hussain, H., Gabrielli, V., Koev, T., Iuga, D., Round, A. N., Mikkelsen, D., Gunning, P. A., Warren, F. J., et al. (2019). "High molecular weight mixed-linkage glucan as a mechanical and hydration modulator of bacterial cellulose: Characterization by advanced NMR spectroscopy," Biomacromolecules 20(11), 4180-4190. DOI: 10.1021/acs.biomac.9b01070

Revin, V., Liyaskina, E., Nazarkina, M., Bogatyreva, A., and Shchankin, M. (2018). "Cost-effective production of bacterial cellulose using acidic food industry byproducts," Brazilian Journal of Microbiology 49, 151-159. DOI:

10.1016/j.bjm.2017.12.012

Santos, S. M., Carbajo, J. M., Gómez, N., Ladero, M., and Villar, J. C. (2017). "Modification of bacterial cellulose biofilms with xylan polyelectrolytes," Bioengineering 4(4). DOI: 10.3390/bioengineering4040093

Santos, S. M., Carbajo, J. M., Gómez, N., Quintana, E., Ladero, M., Sánchez, A., ChingaCarrasco, G., and Villar, J. C. (2016). "Use of bacterial cellulose in degraded paper restoration. Part I: Applicationon modelpapers," Journal of Materials Science 51(3), 1541-1552. DOI: 10.1007/s10853-015-9476-0

Sharma, C., and Bhardwaj, N. K. (2019). "Biotransformation of fermented black tea into bacterial nanocellulose via symbiotic interplay of microorganisms," International Journal of Biological Macromolecules 132, 166-177. DOI: 10.1016/j.ijbiomac.2019.03.202

Stanisławska, A. (2016). "Bacterial nanocellulose as a microbiological derived nanomaterial," Advances in Materials Science 16(4), 45-57. DOI: 10.1515/adms- 
2016-0022

Stanisławska, A., Staroszczyk, H., and Szkodo, M. (2020). "The effect of dehydration/rehydration of bacterial nanocellulose on its tensile strength and physicochemical properties," Carbohydrate Polymers 236. DOI:

10.1016/j.carbpol.2020.116023

Tahara, N., Tabuchi, M., Watanabe, K., Yano, H., Morinaga, Y., and Yoshinaga, F. (1997). "Degree of polymerization of cellulose from Acetobacter xylinumBPR2001 decreased by cellulase produced by the strain," Bioscience, Biotechnology \& Biochemistry 61(11), 1862-1865. DOI: 10.1271/bbb.61.1862

Uribe-Padilla, J., Graells, M., Salgado-Valle, J., and Serrano, J. L. (2019). “A viscositymediated model for relating gloss and film thickness of coatings," Progress in Organic Coatings 136, article no. 105195. DOI: 10.1016/j.porgcoat.2019.06.041

Vigentini, I., Fabrizio, V., Dellacà, F., Rossi, S., Azario, I., Mondi, C., Benaglia, M., and Foschino, R. (2019). "Set-up of bacterial cellulose production from the genus Komagataeibacter and its use in a gluten-free bakery product as a case study," Frontiers in Microbiology 10, 1-13. DOI: 10.3389/fmicb.2019.01953

Yamada, Y. (2014). "Transfer of Gluconacetobacter kakiaceti, Gluconacetobacter medellinensis and Gluconacetobacter maltaceti to the genus Komagataeibacter as Komagataeibacter kakiaceti comb. nov., Komagataeibacter medellinensis comb. nov. and Komagataeibacter maltaceti comb.nov.," International Journal of Systematic and Evolutionary Microbiology 64, 1670-1672. DOI: 10.1099/ijs.0.054494-0

Yim, S. M., Song, J. E., and Kim, H. R. (2017). "Production and characterization of bacterial cellulose fabrics by nitrogen sources of tea and carbon sources of sugar," Process Biochemistry 59, 26-36. DOI: 10.1016/j.procbio.2016.07.001

Zeng, M., Laromaine, A., and Roig, A. (2014). "Bacterial cellulose films: Influence of bacterial strain and drying route on film properties," Cellulose 21(6), 4455-4469. DOI: 10.1007/s10570-014-0408-y

Zhu, H., Li, Y., Wang, J., Lin., W., and Chen, Y. (2019). "Enhancement of bacterial cellulose production in Bacillus amyloliquefaciens," IOP Conference Series: Materials Sciences and Engineering 493. DOI: 10.1088/1757-899X/493/1/012036

Article submitted: February 3, 2021; Peer review completed: March 14, 2021; Revised version received and accepted: July 15, 2021; Published: July 21, 2021.

DOI: 10.15376/biores.16.3.6147-6158 